\title{
Article \\ Experimental Investigation and Numerical Modeling of Elastic Modulus Variation with Stress during Hydration and Expansion Process of Static Cracking Agent
}

\author{
Zhaoguo Qiu ${ }^{1}$, You $\mathrm{Ji}^{2}$, Fengpeng Zhang ${ }^{2, *}$ and Guangliang Yan ${ }^{2, *}$ \\ 1 School of Science, Northeastern University, Shenyang 110819, China; qiuzg@mail.neu.edu.cn \\ 2 Key Laboratory of Ministry of Education on Safe Mining of Deep Metal Mines, Northeastern University, \\ Shenyang 110819, China; 1870847@stu.neu.edu.cn \\ * Correspondence: zhangfengpeng@mail.neu.edu.cn (F.Z.); 1710366@stu.neu.edu.cn (G.Y.); \\ Tel.: +86-150-2767-5797 (G.Y.)
}

Citation: Qiu, Z.; Ji, Y.; Zhang, F.; Yan, G. Experimental Investigation and Numerical Modeling of Elastic Modulus Variation with Stress during Hydration and Expansion Process of Static Cracking Agent. Appl. Sci. 2021 11, 3955. https://doi.org/10.3390/ app11093955

Academic Editor: José A.F.O. Correia

Received: 1 April 2021

Accepted: 22 April 2021

Published: 27 April 2021

Publisher's Note: MDPI stays neutral with regard to jurisdictional claims in published maps and institutional affiliations.

Copyright: (c) 2021 by the authors. Licensee MDPI, Basel, Switzerland. This article is an open access article distributed under the terms and conditions of the Creative Commons Attribution (CC BY) license (https:// creativecommons.org/licenses/by/ $4.0 /)$.

\begin{abstract}
Based on the "axial-output method", the time histories of radial and axial expansive pressures during the hydration process of static cracking agent (SCA) in a cylinder with various diameters were obtained by experiments. With the load input taken as the product of the normalized axial expansive pressure and the amplitude coefficient, a finite element model was established to simulate the experimental chemical expansion process of SCA. The relationships between elastic modulus, radial and axial expansive pressures were then obtained. The results indicate that the elastic modulus increases with increasing radial and axial expansive pressures, and then tends to be constant. The effect of Poisson's ratio was discussed with the elastic modulus unchanged. It is shown that the Poisson's ratio is inversely proportional to the amplitude coefficient, and has no effect on the ratio between the axial and radial expansive pressures. Finally, a mechanical model for the variation of elastic modulus with stress during the hydration process of static cracking agent was established in terms of the major principal stress. The model was verified by the experimental results, which can be extended for numerical simulation of SCA expansion under other compressive loading conditions, and then provide practical mechanical parameters for engineering application of SCA.
\end{abstract}

Keywords: static cracking agent; axial-output method; expansive pressure; model for variation of elastic modulus

\section{Introduction}

The static cracking agent (SCA) is also known as the static demolition agent, the soundless cracking agent, or the non-explosive expansive demolition agent, which was first manufactured in Japan. The SCA is a highly expansive powdery cementitious material. It becomes slurry when mixed with a proper amount of water and is then filled into boreholes. The hydration process results in volume expansion, and subsequently expansive pressures on the borehole wall. When the tensile stress is higher than the tensile strength of the surrounding mass to be crushed, cracks occur. With continuous action of expansive pressures, cracks propagate until the surrounding mass is cracked and fractured [1,2].

Compared to cracking by conventional explosives, the expansive pressure can be transferred evenly to the surrounding mass due to the relatively slow hydration process when the SCA is adopted. No blasting vibrations, noises and fly-rocks are generated over the entire cracking process. Therefore, it is called "static blasting" [3,4]. As an important supplement to controlled blasting, the static blasting technique has been widely applied in quarrying, concrete demolition [4], rock excavation [5,6], high slope trimming and other fields [7-9]. Recently, some researchers have applied it in active roof-contacted support of artificial pillars and further extended the application scope of SCA [10]. SCA was also introduced as a method for directly investigating the extent of incipient rock discontinuities [11,12]. 
Currently, the studies on SCA mainly focus on the expansion mechanism [13-15], cracking mechanism [16-18], enhancement of expansive pressure [19-21], controlling the effects of hydration rate and temperature and local controllable cracking [22,23]. Some publications explored superplasticizer [24], amount of mixing water $[25,26]$ and the ambient temperature [26,27] impacts on hydration heat and expansive pressure development. In order to broaden the application of SCA, $\mathrm{Xu}$ et al. [7] presented an innovative SCDA cartridge, which can be applied to fracture rock masses using boreholes in any inclination, dry or wet. Despite many efforts have been made in research and development of SCA, the variation of mechanical parameters with the expansion process of SCA is not clear. Further studies on the evolution law of the mechanical parameters during the hydration process of SCA are necessary to understand characteristics of SCA. However, studies on the evolution law of the mechanical parameters during the hydration process of SCA have been seldom reported.

In this paper, the model experiments of the SCA hydration process in a cylinder with various diameters were conducted to obtain the time histories of radial and axial expansive pressures. Then, a finite element model was established to simulate the experimental chemical expansion process of SCA. In the simulation, the elastic modulus $E$ was adjusted so that the radial and axial expansive pressures can be consistent with the experimental results. Based on the numerical experimental results, the relationships between the elastic modulus, the radial expansive pressure and the axial expansive pressure of SCA hydrated with constant volume were investigated. Based on the above relationships, a mathematical model for the variation of elastic modulus with stress during the hydration process of SCA is established that can be extended for numerical simulation of SCA expansion under other compressive loading conditions.

\section{Materials and Method}

\subsection{Model Experiments}

The test system for the axial-output method is shown in Figure 1, which mainly consists of two parts: the steel cylinder and the automatic load control system for axial confinement, and axial stress measurement. This method constrains the radial displacement so that the displacement occurs in the axial direction. The piston diameter is $0.2 \mathrm{~mm}$ smaller than the cylinder diameter, so that a small gap can be maintained between them and the piston can move freely along the axial direction. The main role of the piston is to seal the SCA slurry in the cylinder, so that the axial restraint can be applied. When the SCA slurry generates expansive pressures in the cylinder, the axial force can be transferred evenly to the load measurement device. The automatic load control system is composed of two parts: the servo-controlled loading machine and the automatic control software. The testing machine can achieve a maximum load of $3000 \mathrm{kN}$. The precision of the load cell is $0.5 \mathrm{kN}$. Taking the cylinder with a diameter of $113 \mathrm{~mm}$ as an example, the measurement precision can reach $0.01 \mathrm{MPa}$. The displacement was measured by an external small-deformation displacement sensor, with the maximum range of $5 \mathrm{~mm}$ and the precision of $0.0001 \mathrm{~mm}$, which can fully satisfy the test requirements. The axial pressure was calculated by dividing the load cell record by the piston area. With the temperature measured by the gauge on the exterior cylinder wall, the circumferential strain was compensated. The axial pressure can then be obtained theoretically according to the cylinder stress theory in elastic mechanics.

In order to obtain the time histories of radial and axial pressures for SCA with equal height-diameter ratio and zero axial displacement, cylinders with various diameters and heights and different SCA charges were considered, as listed in Table 1. The test results are shown in Figure 2.

Figure 2 presents the time histories of radial and axial pressures corresponding to various cylinder diameters. The results indicate that: for any cylinder diameter, the radial and axial pressures increase first and then tend to be steady with time and increase with increasing cylinder diameter. Due to the boundary effect, the ratio between the radial and axial pressures increases with increasing cylinder diameter. Taking the data within $65 \mathrm{~h}$ as an example, the ratio gradually changes from 0.3 to 1 . 


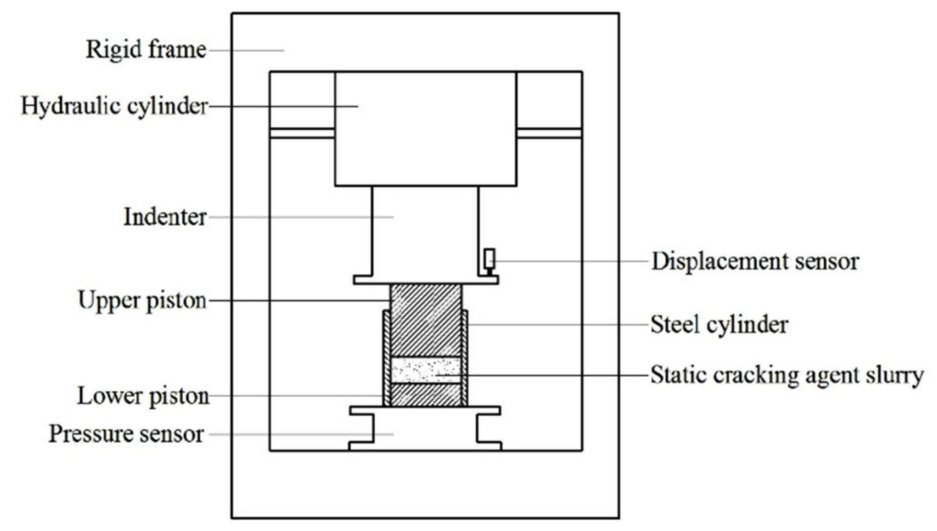

Figure 1. The test principle for the axial-output method.

Table 1. Geometric parameters for cylinder and SCA.

\begin{tabular}{ccccccccc}
\hline Cylinder No. & $\mathbf{1}$ & $\mathbf{2}$ & $\mathbf{3}$ & $\mathbf{4}$ & $\mathbf{5}$ & $\mathbf{6}$ & $\mathbf{7}$ & $\mathbf{8}$ \\
Inner diameter of & 30 & 42 & 50 & 65 & 90 & 113 & 130 & 150 \\
cylinder $(\mathbf{m m})$ & & & & & & & & \\
Piston area $\left(\mathbf{c m}^{\mathbf{2}}\right)$ & 7.065 & 13.847 & 19.625 & 33.166 & 63.585 & 100.237 & 132.665 & 176.625 \\
Slurry height $\left(\mathbf{c m}^{\text {) }}\right.$ & 1.1 & 1.6 & 1.9 & 2.4 & 3.4 & 4.2 & 4.9 & 5.6 \\
Slurry volume $\left(\mathbf{c m}^{\mathbf{3}}\right)$ & 7.772 & 22.155 & 37.288 & 79.598 & 214.599 & 420.995 & 650.059 & 989.100 \\
Slurry mass $(\mathbf{g})$ & 18 & 52 & 87 & 185 & 499 & 980 & 1510 & 2300 \\
\hline
\end{tabular}

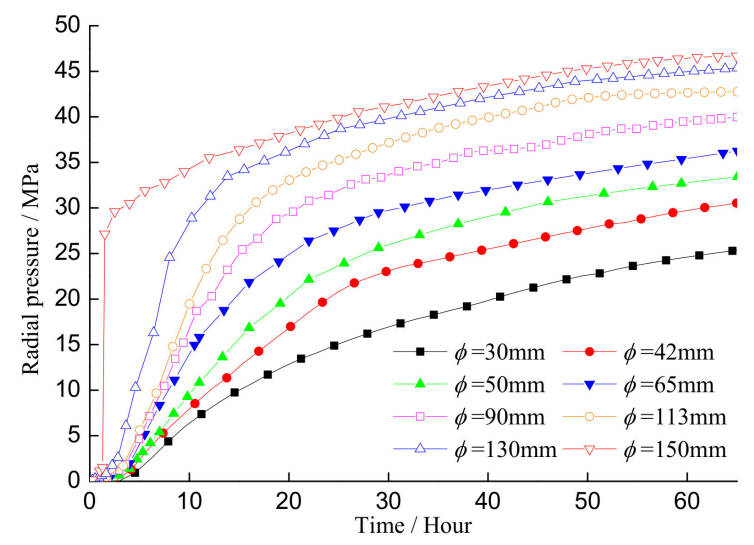

(a)

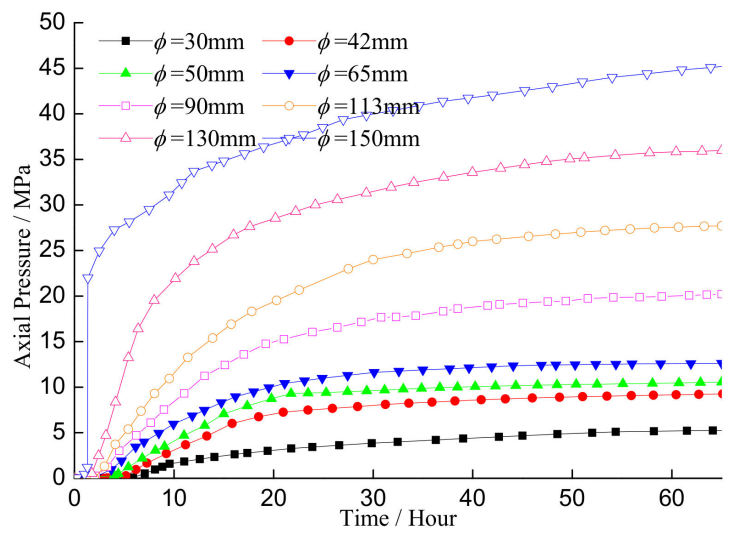

(b)

Figure 2. Time histories of radial and axial expansive pressures obtained by experiments: (a) radial expansive pressure, (b) axial expansive pressure.

\subsection{Numerical Experiments}

In order to back analyze the mechanical parameters of SCA, a finite element model $(1 / 4$ model $)$ is established according to the geometric parameters of steel cylinder and SCA, as shown in Figure 3. The contact relations between the steel cylinder and SCA, piston and SCA are face-to-face smooth contact, and the mean value of the static friction coefficient between the steel cylinder and SCA was determined experimentally as 0.3 . It is assumed that there is no relative displacement at the contact surface between the steel cylinder and the SCA. The steel cylinder and SCA are discretized by 8-node hexahedral elements and 20-node hexahedral elements. Both symmetry surfaces are constrained symmetrically, i.e., the out-of-plane displacements and out-of-plane rotation are constrained. The vertical displacement of the bottom of the steel cylinder, the upper and lower pistons are constrained. The elastic modulus and Poisson's ratio of steel cylinder and piston are set 
as $E=205 \mathrm{GPa}$ and $\mu=0.3$. During numerical simulation, thermal expansion is adopted to simulate the volume expansion during the hydration process of SCA.
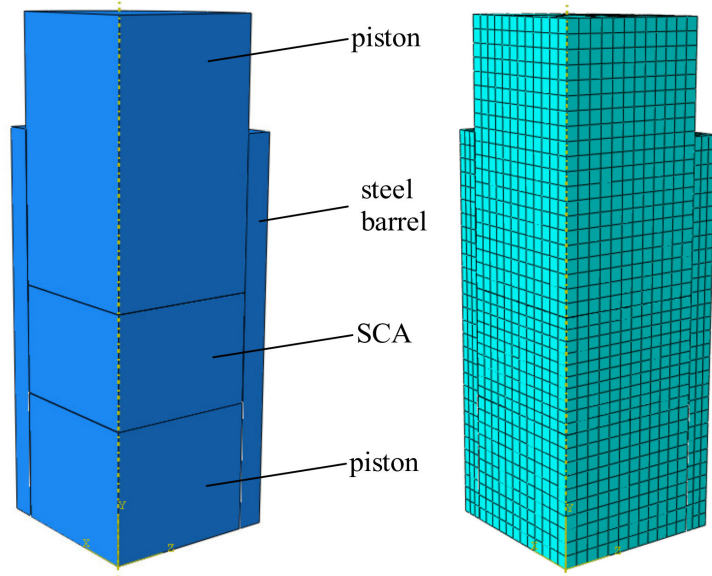

Figure 3. The finite element model.

To facilitate numerical modeling, the normalized deviation method is adopted to normalize the time histories of radial expansive pressure for steel cylinders with varying diameters. The normalized deviation method can be expressed as:

$$
f_{i}(t)=\frac{\sigma_{i}(t)-\sigma_{i, \min }}{\sigma_{i, \max }-\sigma_{i, \min }},(i=1,2,3 \cdots 8)
$$

where $i=1-8$ denotes the number of steel cylinder, $f_{i}(t)$ is the normalized radial pressure, $\sigma_{i}(t)$ is the radial pressure at different moments, $\sigma_{i, \max }$ is the maximum radial pressure, which is taken as $\sigma_{\max }=\sigma(65 \mathrm{~h})$ in this study, $\sigma_{\min }$ is the minimum radial pressure, taken as $\sigma_{\min }=0$ in this study.

The normalized curves are shown in Figure 4. Each curve represents the degree of hydration at different moments for SCA in the cylinder with varying diameter, and also shows the variation of temperature for SCA driven by thermal expansion. The normalized temperature-time curves can be expressed as:

$$
T_{i}(t)=k_{i} f_{i}(t)
$$

where $k_{i}$ is the amplitude coefficient for the model with varying cylinder diameters and $T_{i}(t)$ is the normalized temperature.

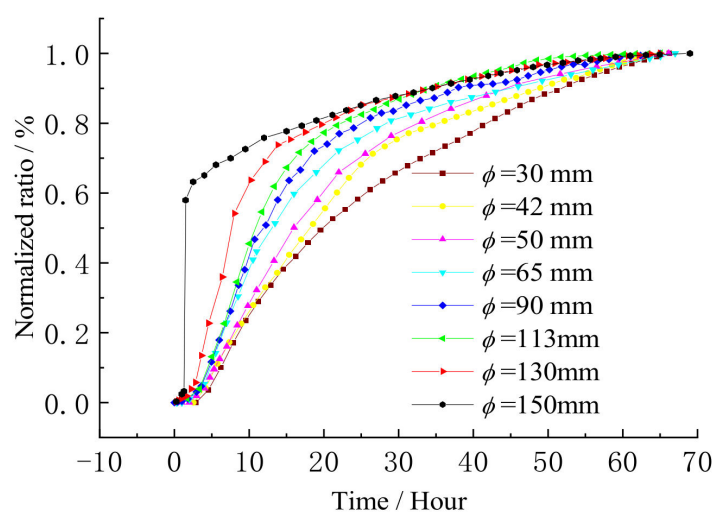

Figure 4. Time histories of amplitude coefficient for radial pressure and temperature for SCA in steel cylinders with varying diameters. 


\section{Discussion}

\subsection{Effect of Elastic Modulus on Axial and Radial Pressures}

During numerical simulation, the temperature curve corresponding to varying cylinder diameters is selected and the amplitude coefficient $k_{i}$ is adjusted so that the simulation results for radial expansive pressure are basically consistent with the test results. The preliminary simulation results suggested that the elastic modulus and Poisson's ratio of the SCA model shall be set as $E=22.5 \mathrm{GPa}$ and $\mu=0.3$, respectively.

The time histories of radial expansive pressure obtained by tests and numerical simulations are shown in Figures 2a and 5a, respectively. It can be seen that the radial expansive pressure in cylinders with varying diameters obtained by numerical simulation has a similar trend with the test results. The expansive pressures are basically the same. The axial expansive pressure data are extracted from the modeling results and compared with the axial pressures measured during the tests, as shown in Figures $2 b$ and $5 b$.

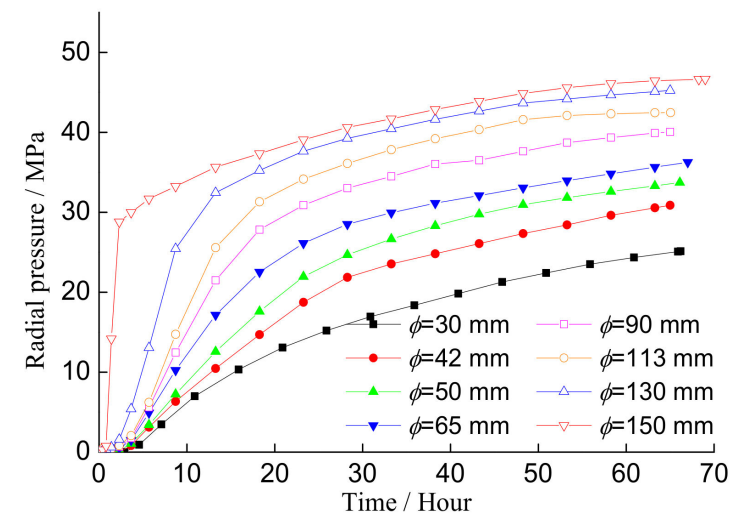

(a)

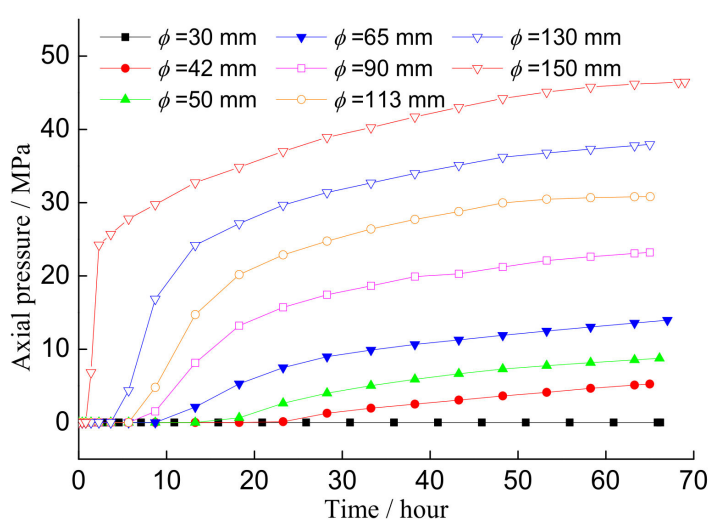

(b)

Figure 5. Time histories of radial and axial expansive pressures obtained by numerical simulation: (a) radial expansive pressure, (b) axial expansive pressure.

When the radial expansive pressure is consistent and the same mechanical parameters are adopted, the axial pressure obtained by numerical simulation has a similar trend with the test results. However, the magnitudes are remarkably different. The axial expansive pressures for various cylinder diameters obtained by numerical simulation are significantly different from the test results. When the cylinder diameter is small $(\phi<65 \mathrm{~mm})$, the measured axial pressure is much higher than that obtained by numerical simulation. When the cylinder diameter is greater than $65 \mathrm{~mm}$, the measured axial pressure is lower than that obtained by numerical simulation.

The above phenomena indicate that the linear elastic model is not good enough to describe the mechanical properties of SCA in cylinders with varying diameter and under different stress conditions. In consideration of the hydration process of SCA with constant volume in a steel cylinder, the expansion of SCA is a gradual compaction process. In this process, the elastic modulus $E$ and the Poisson's ratio $\mu$ may change with increasing expansive pressure. In the following numerical simulations, by adjusting the two key mechanical parameters, i.e., the elastic modulus E and Poisson's ratio $\mu$ of SCA, the effects of the two parameters on the simulation results are investigated. By comparing the simulated axial expansive pressure curves with the test results, the mechanical parameters for numerical simulation are finally determined. First, when the radial pressure is maintained, the relationship between the elastic modulus $\mathrm{E}$ and the axial pressure is discussed based on the dichotomy method, as shown in Figure 6.

It can be known from the distribution of elastic modulus that, the elastic modulus determined by the axial expansive pressures from numerical simulations and tests generally increases with increasing diameter. The amplitude is relatively large. In the model with 
a cylinder diameter of $113 \mathrm{~mm}$, the elastic modulus is close to $36 \mathrm{GPa}$. However, with further increase of cylinder diameter, the elastic modulus drops by a certain degree. This phenomenon does not conform to the general mechanical performance of an elastic body. With increasing diameter, the expansive pressure also increases and the elastic modulus is enhanced or remains unchanged under the action of expansive pressure.

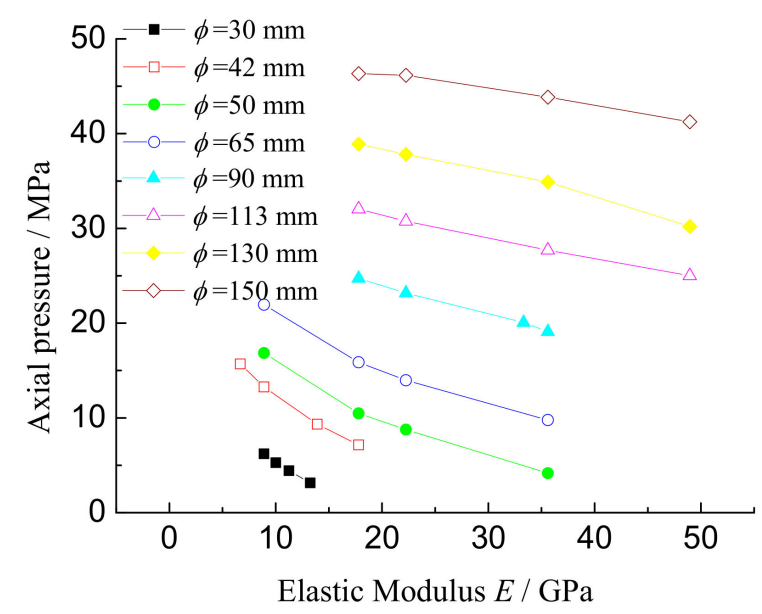

Figure 6. Relationship between simulated axial expansive pressure and elastic modulus.

It can be seen from Figure 6 that: for the models with smaller cylinder diameter $(\phi \leq 65 \mathrm{~mm})$, the elastic modulus varies in a small range with the change of axial expansive pressure. The calculation results show that, in the models with cylinder diameter of $30 \mathrm{~mm}$, $42 \mathrm{~mm}, 50 \mathrm{~mm}$ and $65 \mathrm{~mm}$, the average elastic modulus is $2.199 \mathrm{GPa}, 1.999 \mathrm{GPa}, 2.11 \mathrm{GPa}$ and $2.19 \mathrm{GPa}$, respectively, when the expansive pressure varies by 1.0 MPa. For cylinder diameters larger than $65 \mathrm{~mm}$, the elastic modulus increases more rapidly with the axial expansive pressure. In the models with cylinder diameter of $90 \mathrm{~mm}, 113 \mathrm{~mm}$, and $130 \mathrm{~mm}$, the average elastic modulus is $3.162 \mathrm{GPa}, 4.425 \mathrm{GPa}$ and $3.585 \mathrm{GPa}$, respectively. When the diameter is $150 \mathrm{~mm}$, the average elastic modulus increases to $6.132 \mathrm{GPa}$. The reason for above phenomenon is that the hydration process of SCA is a compaction process. During the compaction process of SCA, the elastic modulus will first increase with the pressure and then tend to a stable value.

The above numerical results indicate that in models with smaller cylinder diameter, the effect of axial expansive pressure on selection of elastic modulus is trivial, while the effect is more prominent for models with larger cylinder diameter. The errors in axial expansive pressures obtained by physical tests are amplified for determination of elastic modulus. The amplification factor increase with increasing diameter. The analysis shows that: for the models with larger cylinder diameter $(\phi \geq 113 \mathrm{~mm})$, the elastic modulus varies in a larger range, which is caused by the amplified errors in the measured axial expansive pressures. In consideration of the general mechanical performance of elastic body, the elastic modulus for models with large cylinder diameter is adjusted appropriately. The elastic modulus is considered to be stable when the diameter is greater than $90 \mathrm{~mm}$, as shown by the fitting curve in Figure 7 .

First, error analysis is performed for the elastic modulus before and after fitting. Meanwhile, according to the fitted elastic modulus curve, the axial expansive pressure corresponding to a cylinder diameter of $90,113,130$ and $150 \mathrm{~mm}$, respectively, is determined. The errors are analyzed by comparing with the axial expansive pressure corresponding to the elastic modulus before adjustment. For four models with various cylinder diameters, the elastic modulus error varies in a large range. When the diameter is $150 \mathrm{~mm}$, the error in elastic modulus reaches $16.7 \%$. However, the corresponding axial expansive pressure error varies in a small range, with the maximum being less than $2.0 \%$. Therefore, it is shown that, 
when the elastic modulus after adjustment is adopted for numerical simulation, the error in the axial expansive pressure is relatively small, as shown in Figure 8.

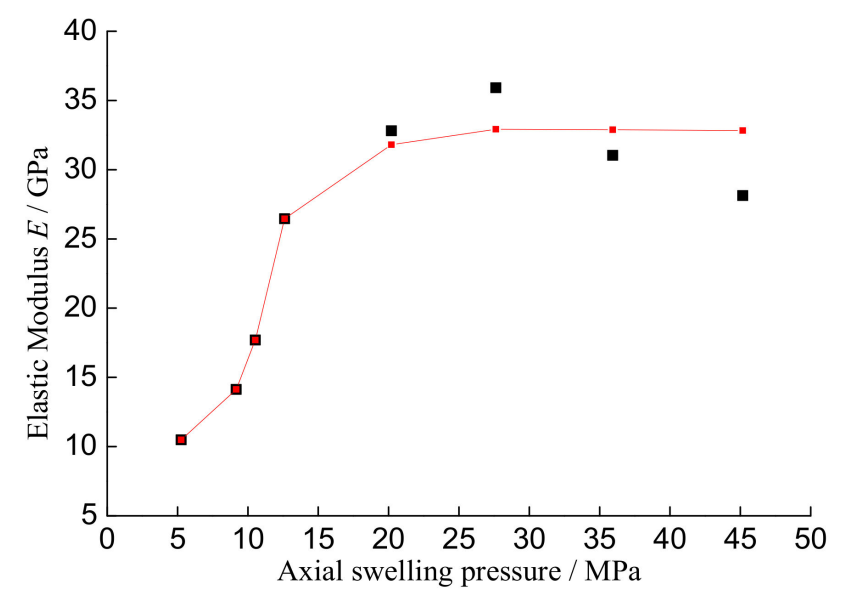

Figure 7. Variation of elastic modulus with axial pressure.

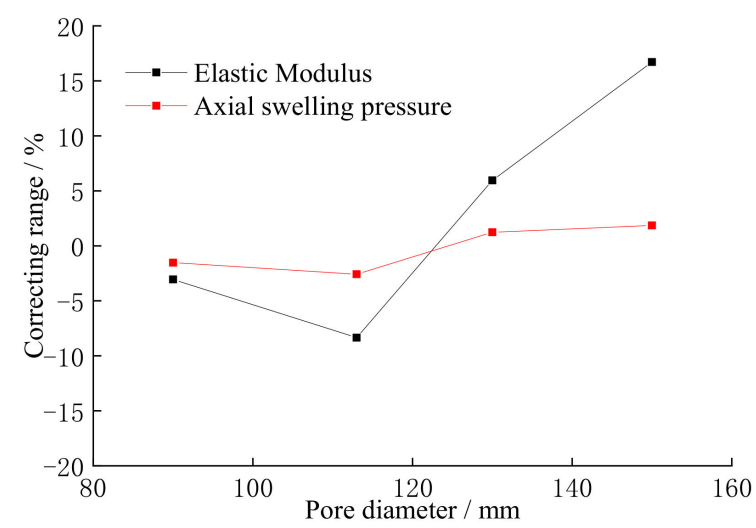

Figure 8. Sensitivity analysis for elastic modulus and axial expansive pressure.

\subsection{Effect of Poisson's Ratio}

The elastic modulus corresponding to various diameters is selected. When the other parameters remain unchanged, the Poisson's ratio $\mu$ of the SCA model is varied so as to simulate the effect of Poisson's ratio. The simulation results show that the axial expansive pressure increases linearly with the Poisson's ratio. In order to keep the simulated radial expansive pressure consistent with the measured data, the amplitude coefficient $k_{i}$ for temperature increase needs to be adjusted. The amplitude coefficient $k_{i}$ after adjustment decreases linearly with increasing Poisson's ratio. Taking the simulation results for models with cylinder diameter of 50 and $90 \mathrm{~mm}$ for example, the relationships between Poisson's ratio and the amplitude coefficient are shown in Figure 9.

Based on the above simulation results, the axial expansive pressures corresponding to various Poisson's ratios are compared. Given the simulated radial expansive pressures being consistent with the measured values, the relationships between Poisson's ratio and the axial expansive pressure for models with cylinder diameter of $50 \mathrm{~mm}$ and $90 \mathrm{~mm}$ are plotted in Figure 10. It can be seen that the Poisson's ratio has little impact on the axial pressure, which is almost constant. In another word, the ratio between the axial and radial pressure is independent of Poisson's ratio.

\subsection{Comparison of Results Obtained with Literature}

It is known from the previous studies that the expansion pressure of SCA ranged from $20-70 \mathrm{MPa}[7,23,24,27,28]$. Similar to the results of previous studies, the axial and 
radial expansion pressure of SCA reached about $48 \mathrm{MPa}$ in this study. Meanwhile, both model experiments and numerical experimental results show that the expansion pressure gradually increases with increasing diameter, which is consistent with the results of $[23,24]$. By increasing the diameter of SCA, a higher expansion pressure can be obtained. However, it should be noted that the relationship between the expansion pressure and diameter of SCA is not linear.

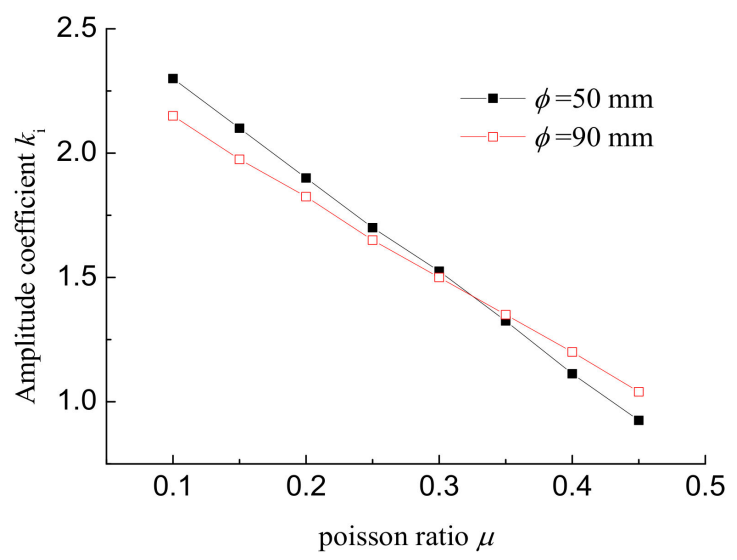

Figure 9. Relationship between Poisson's ratio and amplitude coefficient.

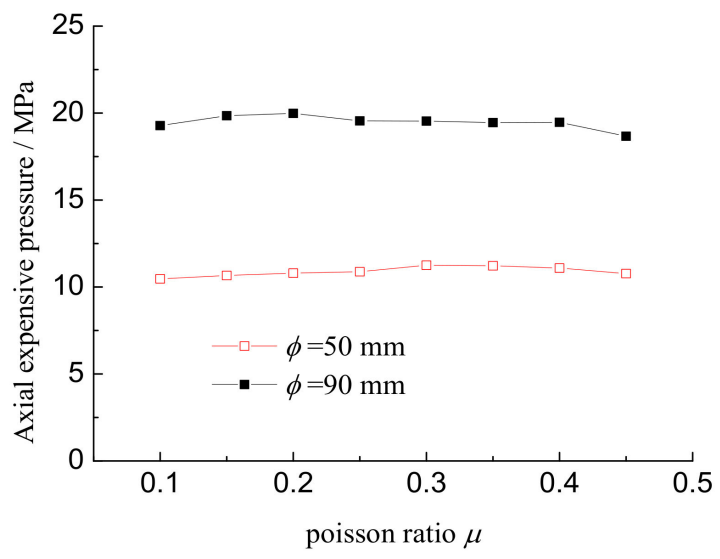

Figure 10. Relationship between Poisson's ratio and axial expansive pressure.

The elastic modulus of SCA is greatly affected by the constraint conditions. Under unconstrained conditions, the elastic modulus of SCA after hydration is small, about $20 \mathrm{MPa}[28,29]$. Under constrained conditions, the elastic modulus of SCA can reach dozens of GPa. This shows that constraint condition, i.e., the application environment, is important factors that affect the mechanical parameters of SCA.

Due to the limitation of measurement methods, there are few studies on the evolution law of mechanical parameters in the hydration process of SCA. In this study, based on the experimental results, the evolution law of mechanical parameters is inversed by using the finite element model, which is helpful to understand the hydration process of SCA.

\section{Mathematical Model for Variation of Elastic Modulus}

It shall be noted that compression is positive in this paper. It is known from the above analyses that different pressures correspond to different elastic moduli. However, the above analysis is based on the assumption that the elastic modulus for the same cylinder diameter is the same. In the real case, the internal stress in SCA increases with the hydration process under constant volume. Correspondingly, the elastic modulus inevitably changes from a low value to a high value and finally a constant value. In order to investigate 
the mechanical mechanism of the entire hydration process of SCA, a model reflecting the change of elastic modulus with stress shall be established. The relationship between the major principal stress and the elastic modulus under various radial (axial) pressures is plotted in Figure 11.

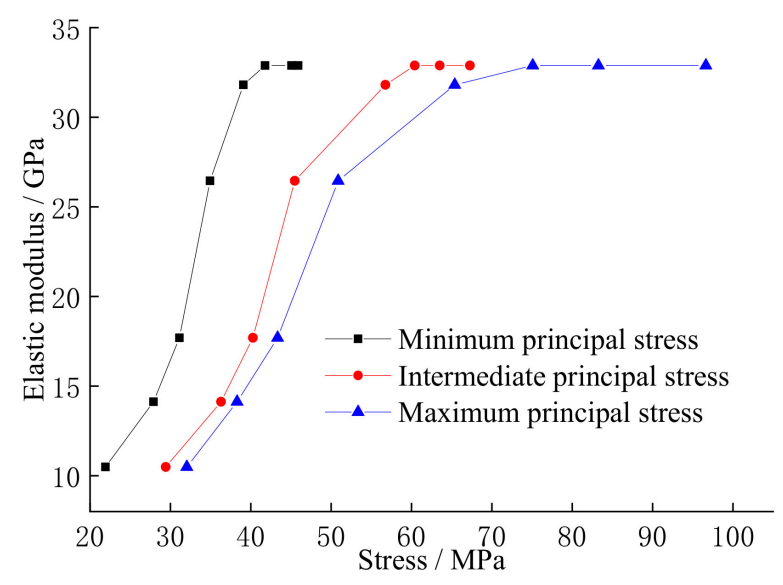

Figure 11. Relationship between the major principal stress and elastic modulus.

In the following section, the relationship between the stress and elastic modulus will be established according to the major principal stress. The major principal stress in Figure 11 is normalized. As the maximum principal stress is $95.09 \mathrm{MPa}$, the two stresses higher than 75.09 $\mathrm{MPa}$ are ignored for normalization. The elastic modulus and the normalized stress are shown in Table 2, which is the model for variation of elastic modulus with the major principal stress.

Table 2. Relationship between normalized stress and elastic modulus.

\begin{tabular}{ccccccccccc}
\hline Normalized Stress $\sigma_{N 0}$ & 0 & 0.233 & 0.33 & 0.427 & 0.51 & 0.578 & 0.677 & 0.871 & 1 \\
\hline Elastic modulus $(G P a)$ & 1.2 & 2.5 & 5.0 & 10.49 & 14.13 & 17.695 & 26.457 & 31.807 & 32.885 \\
\hline
\end{tabular}

The first 3 columns in Table 2 are obtained by extending the curve in Figure 11, instead of the measured data. Limited by the test conditions, the values in the first 3 columns are inaccurate. In order to facilitate its application, the data in Table 2 are fitted by a Boltzman function in Equation (3).

$$
E\left(\sigma_{N}\right)=a_{2}+\frac{\left(a_{1}-a_{2}\right)}{1+e^{\left(\frac{\sigma_{N}-\sigma_{N 0}}{a_{3}}\right)}}
$$

where $a_{1}, a_{2}, a_{3}$ and $\sigma_{N 0}$ are constants.

The initial data and the fitting curve are shown in Figure 12. At this moment, the corresponding constants are: $a_{1}=1.1134, a_{2}=32.885, \sigma_{N 0}=0.54644$ and $a_{3}=0.10989$. Equation (3) is the model for variation of elastic modulus with the major principal stress where the Poisson's ratio is equal to 0.1. In fact the relationship between the Poisson's ratio and the expansion coefficient of SCA is linear. The value of Poisson's ratio doesn't affect the model precision. In order to verify the model, a subroutine module for variation of elastic modulus is compiled based on the USDFLD subroutine module of ABAQUS. The radial and axial pressures for models with various cylinder diameters are simulated and plotted in Figure 13. It can be seen from Figure 13 that the simulation results obtained by the model for variation of elastic modulus are in good agreement with the measured data, indicating that this model is feasible for investigating the expansion process of SCA in a cylinder with volume constraint. 


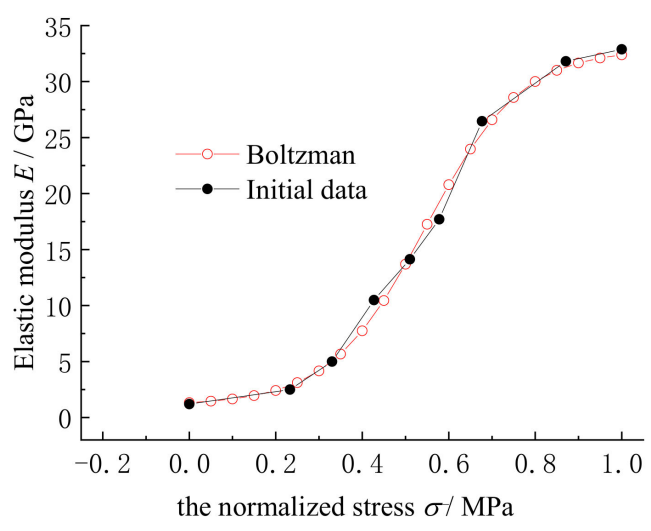

Figure 12. Data fitting for the relationship between normalized stress and elastic modulus.

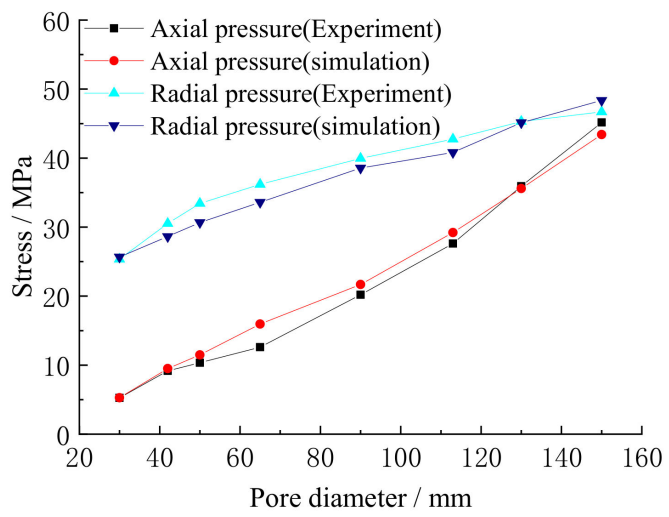

Figure 13. Radial and axial pressures for models with varying cylinder diameters.

\section{Conclusions}

In this study, the time histories of radial and axial expansive pressures for the entire hydration process of SCA in cylinders with various diameters were first obtained based on the "axial-output method". The chemical reaction and expansion process of SCA was then simulated by thermal expansion. Taking the product of the normalized axial expansive pressure and the amplitude coefficient as the load input, a finite element model for the physical tests and the mathematical model for variation of elastic modulus with the major principal stress were established. The following conclusions can be drawn:

(1) Under the volume constraint condition, the hydrated SCA is compacted with increasing expansive pressures. As a result, the elastic modulus increases first and then tends to be stable at a constant value. When the expansion pressure is greater than $20 \mathrm{Mpa}$, the elastic modulus is stable at about $36 \mathrm{Gpa}$.

(2) When the elastic modulus remains unchanged, both the radial and axial expansive pressures of SCA increase linearly with increasing Poisson's ratio. When the radial pressure remains unchanged, the Poisson's ratio and the amplitude coefficient are inversely proportional and have no impact on the ratio between axial and radial pressures.

(3) A mathematical model for variation of elastic modulus with the major principal stress is established based on the variation laws of elastic modulus and Poisson's ratio of the SCA model. The modeling results are in good agreement with the measured data. Hence, this model is feasible for investigating the expansion process of SCA in a cylinder with constant volume and providing practical mechanical parameters for engineering application of SCA.

Author Contributions: This paper is a result of the collaboration of all co-authors. Z.Q. conceived and designed the study; G.Y. and Y.J. conducted the experimental; G.Y. drafted the manuscript; F.Z. revised the manuscript. All authors have read and agreed to the published version of the manuscript. 
Funding: This research was funded by the State Key Research Development Program of China (Grant No. 2017YFC0602902). The fourth author also wish to express his thanks to China Scholarship council (Grant No. 202006080082) for the support.

Conflicts of Interest: The authors declare no conflict of interest.

\section{List of Symbols}

$\begin{array}{ll}i & \text { Number of steel cylinder } \\ t & \text { Time (hour) hydration and expansion of static cracking agent } \\ f_{i}(t) & \text { Normalized radial pressure at different time } \\ \sigma_{i}(t) & \text { Radial pressure at different time } \\ \sigma_{i, \max } & \text { Maximum radial pressure, which is taken as } \sigma_{\max }=\sigma(65 \mathrm{~h}) \\ \sigma_{i, \min } & \text { Minimum radial pressure, which taken as } \sigma_{\min }=0 \\ \Phi & \text { Cylinder diameter } \\ k_{i} & \text { Amplitude coefficient } \\ T_{i}(t) & \text { Normalized temperature. } \\ E & \text { Elastic modulus } \\ \mu & \text { Poisson's ratio } \\ a_{1}, a_{2}, a_{3} & \text { Constants } \\ \sigma_{N 0} & \text { Normalized stress }\end{array}$

\section{References}

1. Tang, L.X.; Tang, C.A.; Tang, S.B.; Cui, Y.H.; Song, L. Physical experiment and numerical simulation on effect of soundless cracking agent. Chin. J. Geotech. Eng. 2005, 27, 437-441.

2. Swanson, D.; Labuz, J. Behavior of a calcium oxide-based expansive cement. Concr. Sci. Eng. 1999, 1, 166-172.

3. Guo, R.P.; Yang, Y.Q. Swelling mechanism and controllability of SCA. J. China Coal Soc. 1994, 19, 478-485.

4. Laefer, D.F.; Ambrozevitch-Cooper, N.; Huynh, M.; Midgette, J.; Ceribasi, S.; Wortman, J. Expansive fracture agent behaviour for concrete cracking. Mag. Concr. Res. 2010, 62, 443-452. [CrossRef]

5. Schram, C.M.; Hinze, J. Fracturing of rock using expansive soundless chemical demolition agents. In Proceedings of the Foundation Engineering: Current Principles and Practices, Evanston, IL, USA, 25-29 June 1989; pp. 447-458.

6. Arshadnejad, S.; Goshtasbi, K.; Aghazadeh, J. A model to determine hole spacing in the rock fracture process by non-explosive expansion material. Int. J. Miner. Metall. Mater. Struct. 2011, 18, 509-514. [CrossRef]

7. Xu, S.; Hou, P.Y.; Li, R.R.; Cai, M. An Experimental Study on the Mechanical Properties and Expansion Characteristics of a Novel Self-Swelling Cartridge for Rock Breakage. Rock Mech. Rock Eng. 2021, 54, 819-832. [CrossRef]

8. Xu, S.; Hou, P.Y.; Cai, M.; Li, Y.H. An experiment study on a novel selfswelling anchorage bolt. Rock Mech. Rock Eng. 2019, 52, 4855-4862. [CrossRef]

9. Natanzi, A.S.; Laefer, D.F.; Zolanvari, S.M.I. Selective demolition of masonry unit walls with a soundless chemical demolition agent. Constr. Build. Mater. 2020, 248, 118635. [CrossRef]

10. Li, K.M.; Li, Y.H.; Jing, H.D. Evaluation of the Active Support and Yielding Bearing Properties of Artificial Pillars Supporting a Stope Roof Using 3DEC Numerical Simulation. Adv. Civ. Eng. 2019, 2, 1-7. [CrossRef]

11. Shang, J.; Hencher, S.R.; West, L.J.; Handley, K. Forensic Excavation of Rock Masses: A Technique to Investigate Discontinuity Persistence. Rock Mech. Rock Eng. 2017, 50, 2911-2928. [CrossRef]

12. Shang, J.; West, L.J.; Hencher, S.R.; Zhao, Z. Tensile strength of large-scale incipient rock joints: A laboratory investigation. Acta Geotech. 2018, 13, 869-886. [CrossRef]

13. Inada, Y.; Matsuki, S.; Yokota, K. Basic research on static crushing by utilizing expansive agents. Min. Metall. Inst. Jpn. 1988, 104, 337-344. [CrossRef]

14. Fukui, H.; Tsukada, K. Static demolition agent by calcium oxide. Sci. Technol. Energ. Mater. 2003, 64, $25-31$.

15. Ishibashi, K.; Watanabe, A.; Harada, T.; Idemitsu, T. Design method for demolition of concrete with non-explosive demolition agent. Trans. Jpn. Concr. Inst. 1985, 119-126.

16. Fukui, H.; Matsumoto, K.; Tsukada, K.; Hansaki, K. Stress analysis by finite element method around parallel holes occurred by static demolition agent. Sci. Technol. Energ. Mater. 2005, 66, 255-259.

17. Cho, H.; Nam, Y.; Kim, K.; Lee, J.; Sohn, D. Numerical simulations of crack path control using soundless chemical demolition agents and estimation of required pressure for plain concrete demolition. Mater. Struct. 2018, 51, 169.1-169.13. [CrossRef]

18. Arshadnejad, S.; Niu, J. Birth of the first crack and its growth under incremental static loading between two holes in brittle rocks. J. Earth Eng. 2014, 1, 1-15.

19. Shang, J.; Zhao, Z.; Aliyu, M.M. Stresses induced by a demolition agent in non-explosive rock fracturing. Int. J. Rock Mech. Min. Sci. 2018, 107, 172-180. [CrossRef]

20. Harada, T.; Soeda, K.; Idemitsu, T.; Watanabe, A. Characteristics of expansive pressure of an expansive demolition agent and the development of new pressure transducers. Proc. Jpn. Soc. Civ. Eng. 1993, 478, 91-100. 
21. Soeda, K.; Harada, T.; Kanbayashi, M.; Hosono, K. Measuring method of expansive pressure of expansive demolition agent using flush diaphragm type pressure transducer. Proc. Jpn. Soc. Civ. Eng. 1993, 478, 145-148.

22. Tang, Y.B.; Yuan, L.; Xue, J.H.; Duan, C.R. Experimental study on fracturing coal seams using cao demolition materials to improve permeability. J. Sustain. Min. 2017, 16, 47-54. [CrossRef]

23. Gambatese, J.A. Controlled concrete demolition using expansive cracking agents. J. Constr. Eng. Manag. 2003, 129, 98-104. [CrossRef]

24. Hinze, J.; Nelson, A. Enhancing performance of soundless chemical demolition agents. J. Constr. Eng. Manag. 1996, 122, 193-195. [CrossRef]

25. Hinze, J.; Brown, J. Properties of soundless chemical demolition agents. J. Constr. Eng. Manag. 1994, 120, 816-827. [CrossRef]

26. Li, Y.; Ma, Q.Y. Test and analysis on reaction temperature variation of static cracking agent. Chin. J. Undergr. Space Eng. 2013, 9 , 1289-1292.

27. Natanzi, A.S.; Laefer, D.F.; Connolly, L. Cold and moderate ambient temperatures effects on expansive pressure development in soundless chemical demolition agents. Constr. Build. Mater. 2016, 110, 117-127. [CrossRef]

28. Silva, V.R.S.D.; Ranjith, P.G.; Perera, M.S.A.; Wu, B.; Rathnaweera, T.D. The influence of admixtures on the hydration process of soundless cracking demolition agents (SCDA) for fragmentation of saturated deep geological reservoir rock formations. Rock Mech. Rock Eng. 2019, 52, 435-454. [CrossRef]

29. Silva, V.R.S.D.; Ranjith, P.G.; Perera, M.S.A.; Wu, B.; Rathnaweera, T.D. Investigation of the mechanical, microstructural and mineralogical morphology of soundless cracking demolition agents during the hydration process. Mater. Charact. 2017, 130, 9-24. [CrossRef] 